\title{
Sequence Effects in Service Bundles: Implications for Service Design and Scheduling
}

\author{
Michael Dixon, Naval Post Graduate School \\ Rohit Verma, Cornell University
}

\begin{abstract}
Researchers in several academic disciplines have investigated the effect of the sequence of pleasure and pain on the customer in service, experience, or healthcare-related interactions. Specifically, past research from psychology, behavioral economics, and other related fields suggests that the sequence effect can significantly impact a customer's overall impression of a service interaction. In this article, we test the influence that the sequence of discrete events separated by several days or weeks plays on customers' assessment of service bundles. If the relative importance of the sequence effect for discrete bundles is known, then a service designer and event scheduler can optimize and develop a better sequence of interactions for the customers, leading to higher satisfaction, loyalty, and repurchase. Using an extensive multi-year ticket purchase database from a world-renowned performing arts venue, we develop and test econometric models to predict season ticket subscription repurchase. The estimated models show that sequence effects do indeed play a significant role in determining customer repurchase of subscriptions. These results have important implications for effective service design and capacity planning for a wide range of service industries. This article suggests both managerial implications and future research opportunities related to sequence effects in service operations.
\end{abstract}

\section{Introduction}

Effective service design and capacity scheduling involves developing a service concept that appeals to end users while considering operational constraints (e.g., Pullman et al., 2000; Verma et al., 2001; Goodale et al., 2003). Furthermore, past research has emphasized that operations management's role in designing a service concept involves understanding "what" should be done and "how" it should be done (e.g., Goldstein et al., 2002). Exploring the methods and frameworks of "what" and "how" has been the focus of much of the service design research; however, less explored is the importance of the 
timing decisions within a service delivery. In other words, "when" should customers experience different segments or components of a service has not been explored. Specifically, past research in service operations management has not discussed the relative importance of the sequence of pleasure and pain and associated interactions within service design.

Based on research conducted in other academic disciplines, some operations management scholars have suggested that the sequence of events within a service can influence customer's overall perception of quality and satisfaction (e.g., Chase and Dasu, 2001, 2008; Cook et al., 2002). Specifically, Chase and Dasu (2001) suggest various strategies for sequencing including placing the lowest point or bad news at the beginning of the service encounter, ending the service on a high note, and improving the experience over time. Furthermore, behavioral economics researchers such as Ariely and Carmon (2000) have reviewed the sequence-related research and suggested several characteristics of experiences that may influence customers' assessments and future behavior. They state that experiences can be perceived as continuous or discrete, and evaluation of the individual parts of an experience can be done retrospectively, prospectively, and in real time.

In this article, we explore the impact of naturally occurring (non-experimentally altered) sequences of discrete service interactions on future customer choice behavior using a prospective view. Using a comprehensive multi-year ticket purchase database from a world-renowned performing arts venue, we test the impact of event sequence on customer repurchase of subscription packages. Using econometric modeling, we estimate the impact of the placement of high-utility events and the trend of event utilities has on the probability of subscription repurchases.

This article contributes to research related to event scheduling and planning, service design, and behavioral decision-making, and expands our understanding of the role of sequence in planning and placement of different components of a service bundle. We believe this paper is the first within the operations management literature that explores the above research issues by using a large archival dataset and that attempts to quantify the impact of service sequence on customer behavior.

The remainder of this article is organized in the following manner: first, we provide a review of the literature related to service bundling and sequence-related behavioral research; second, we present our theoretical framework and hypotheses; third, we describe our research design and analysis approach; fourth, we present our results and associated discussion; and, lastly, we discuss theoretical and managerial implications of this research. 


\section{Literature Review}

\section{Service Bundling}

We address the temporal sequence of events within the context of a service bundle, that is, a combination of a number of different services sold in one package. Product (goods and service) bundling is a heavily researched topic in marketing (e.g., Guiltinan, 1987; Harlam et al., 1995; Stremersch and Tellis, 2002; Gaeth et al., 1991). This practice is common across many service industries; for example, online travel agencies offer packages including airfare, ground travel, and lodging; telecommunications and cable companies offer packages with several different services at one price; performing arts and sporting venues sell season subscriptions that include tickets to a number of events; and multi-day conferences and retreats are often bundled together to include food, lodging, and a series of workshops, seminars, and related activities.

Some service bundles are created by combining a number of different services that are intended to be used simultaneously or concurrently. For example, for one monthly charge, telecommunication firms provide Internet, cable television, and home telephone services as a service bundle for which individual items can all be used at the same time. Other service bundles are created by placing similar discrete services together in a way that they have to be experienced across time or sequentially. For example, a course taught over 12 weeks may have 12 separate class sessions, and a cruise ship package may include 5 days of separate experiences at different locations. Similarly season ticket sales for performing arts or sporting events include a number of different events experienced across multiple days within a season. At times, the event sequence of a service bundles could be constrained; for example, the 5-day cruise typically includes visits to different islands in a physically linear fashion. However, in some other service bundles, the sequence is not assumed to be fixed or at least not entirely fixed; for example, the schedule of performances within a performing arts season subscription can be altered as necessary. These types of service bundles provide ideal testing ground for sequence-related behavioral research because the sequence of the discrete segments can be changed and the impact evaluated.

Different hierarchical levels of service bundling effectively act as a pricing rate fence; for example, a cell phone company that bundles phone, texting, and Internet access can charge different prices for different combinations of bundles. Thus, operations management researchers to date have primarily concerned themselves with revenue management or pricing issues surrounding product (goods and service) bundling (e.g., Bitran and Caldentey, 2003; Bitran and Ferrer, 2007; Aydin and Ziya, 2008), 
and supply chain issues of supplier bundling, or product mix purchasing (Schoenherr and Mabert, 2008; Rosenthal et al., 1995). From an economic perspective, customers purchase bundles because their reservation prices for all individual elements are met; that is, the actual price for high-demand elements is lower than the reservation price, so the surplus is transferred to the less desired element of the bundle.

In a related research stream, a number of procedures to understand "optimal" product and service attributes have been developed to find an attribute mix that maximizes sales, market share (e.g., Green and Krieger, 1989; Shocker and Srinivasan, 1979; Ho and Zheng, 2004), or profit (Green and Krieger, 1991; Morgan et al., 2001; Moore et al., 1999; Raman and Chhajed, 1995). Other researchers have developed attribute mix optimization models while considering operating constraints such as capacity (Pullman and Moore, 1999), production costs (Moore et al., 1999), waiting time and labor scheduling (Pullman et al., 2000), and operational difficulty (Verma et al., 2001). This stream of research has contributed to an understanding of consumers' choice of product and service attributes; however, to our knowledge, none of the optimization models have considered the sequence-related attributes of service delivery. While this article does not attempt to optimize a service bundle, it is the first step in understanding what impact the service sequence might play in optimal bundles.

Behavioral researchers have often broadly used the term "experience" to mean anything that would provoke a physiological or emotional response. Within the service management literature, there has been an effort to distinguish a service offering whose purpose is to evoke an emotion (Pullman and Gross, 2004; Voss, 2004; Zomerdijk and Voss, 2010; Voss et al., 2008). Others (Grove and Fisk, 2001; Pine and Gilmore, 1998) have compared these experience-centric operations to theater productions, comparing front-line servers to actors, physical surroundings to stages, and customers to audience members. Voss et al. (2008) concluded that operations management takes on the role of a choreographer, carefully planning and supervising service delivery in order to evoke a specific emotional state from a customer at a specific time. The metaphor of a choreographer is useful in helping researchers understand the role operations management takes in complex service environments that attempt to produce emotional experiences. Just like a choreographer, operations managers must deliberately and explicitly consider and define the settings, actions, timings, and sensory elements (sound, light, and smell) that lead to a desired experience. Our research investigates whether it is useful to consider one of these elements-timing-across a time-elapsing service bundle with discrete experiences. 


\section{Sequence Effects of Service Bundles}

Behavioral economics researchers have shown that instead of summing or averaging the perception of all parts of an experience, gestalt characteristics are used as cues that, in turn, are used to evaluate the entire experience (Fredrickson and Kahneman, 1993; Loewenstein and Prelec, 1993). Traditionally, this stream of research considers the end-state perception, most salient-state perception (Ariely, 1998; Baumgartner et al., 1997; Kahneman et al., 1993), and overall trend of an experience profile (Ariely, 1998; Ariely and Zauberman, 2003; Hsee et al., 1991). (For a review of this stream of literature, see Ariely and Carmon, 2000; Chase and Dasu, 2001; Bitran et al., 2008.)

An experience profile (Ariely and Carmon, 2000) considers the value, intensity, utility, or disutility of all the different episodes of a time-elapsing experience. The end-state perception, often called the end effect, is the state at the end of an experience; the most salient or peak effect is the highest point on the experience profile; and the trend effect is a measure of the overall development of the hedonic qualities of the experience over time and is often measured as the slope of the linear line through all points on the profile. In addition to these three effects, researchers have identified other effects found to impact perception in certain scenarios. For example, when multiple high-value events were scheduled, researchers found a preference to spread them out over time (Loewenstein and Prelec, 1993; Loewenstein, 1987; Thaler and Johnson, 1990), also known as the spread effect. Additionally, other researchers have investigated the importance of placement of the salient activities relative to the beginning and end of experience and perceived progress toward a desired end state (Soman and Shi, 2003; Soman, 2003; Carmon and Kahneman, 1996). In this article, we refer to all of these known effects collectively as sequence effects.

Marketing researchers have used the above constructs in explaining how customer expectations are formed and how satisfaction with a product (good or service) is expressed (e.g., Oliver, 1980; Parasuraman et al., 1985). However, within the operations management literature, sequence effects have been less researched. In their seminal book Service Breakthoughs: Changing the Rules of the Game, Heskett et al. (1990) discussed the idea of the "service bookend" and emphasize the need for services to provide not only a strong ending, but also a strong beginning. Similarly, Johnston (1995) proposed that exceeding a customer's expectation early in an encounter is more likely to delight the customer throughout the service encounter because the customer is primed to see good service. Chase and Dasu $(2001,2008)$ suggested that behavioral research and sequence effects ought to be considered in service design; however, they did not provide any additional empirical evidence. They did, however, propose that an upward trend and a strong ending are more important than a strong beginning (Chase, 2004). 
Other researchers have shown through experimentation (Hansen and Danaher, 1999) and service content analysis (Verhoef et al., 2004) that an upward trend of sequence performance leads to higher perception of quality and satisfaction; however, these studies only tested for a change in performance level across a fixed sequence, not for changes in the sequence of the process itself, that is, the service process remained unchanged and only the performance levels changed. Bolton et al. (2006) have shown that more recent service encounters as well as "going the extra mile" or extremely favorable experiences influence system support service contract renewals. More recently, Bitran et al. (2008) further refined a conceptual framework of duration in a service encounter and how it applied to profitability. They cited behavioral literature as it applied to duration and the sequence of an encounter and concluded by calling for more varying techniques of empirical-based evidence across different industries, contexts, and research methodologies.

Our research adds to the past research in operations management and marketing in several ways. First, we are interested in the sequence of discrete bundled experiences as opposed to a single service encounter. Second, we hope to provide support for service scheduling's impact on customer behavior. Finally, we test for the presence of sequence effects with econometric modeling. Doing so allows us to uncover sequence effects in a naturalistic archival data set.

\section{Sequences of Discrete Experiences}

Traditional sequence-related research has often taken place within the context of one continuous experience; for example, a medical procedure (Ariely and Carmon, 2000; Kahneman et al., 1993; Redelmeier and Kahneman, 1996), controlled discomfort experiment (Fredrickson and Kahneman, 1993; Ariely, 1998), queuing (Carmon and Kahneman, 1996), or a service call to a financial services call center (Verhoef et al., 2004). Ariely and Zauberman $(2003,2000)$ claim that the perceived continuity of a sequence should impact whether or not sequence effects are used in evaluations of experiences. They found that, as the level of perceived continuity within an experience increases, so too does the importance of some of the specific sequence effects in predicting overall evaluations. Similarly, Loewenstein and Prelec (1993) state that when events are separated in time, they may not be considered a sequence.

However, other research has shown evidence of sequence effects in temporally distant and discrete experiences; for example, gift giving in financial services (Haisley et al., 2011), payment sequences for auto repair and vacations (Langer et al., 2005), timing of repair services performed in a service contract (Bolton et al., 2006), and a lifetime of future wages (Loewenstein and Sicherman, 1991). 
One explanation for why sequence effects were found in these contexts even though they are temporally distant and discrete is their degree of cohesion. Miron-Shatz (2009) found that when asked to evaluate a multi-episode sequence that had no apparent cohesiveness (events from the previous day), simple averages better explained overall evaluations than sequence effects. She suggests that multi-episode sequences with stronger levels of perceived cohesiveness will likely have different results. In this study, we are interested in sequences within time-elapsing service bundles. The offering of a service bundle could be perceived in one of two ways: either as a series of connected episodes or as a convenient way to purchase several separate events. Differing levels of assumed cohesiveness between episodes in a service bundle is an important factor to be considered in future research. Past researchers that have approached the subject have only tested breaking up a continual experience into smaller pieces with temporal space between them (Ariely and Zauberman, 2003). To our knowledge, outside of temporal space, there has been little work considering how different elements of cohesion impact sequence effects. First and foremost among possible different elements of cohesion is the act of bundling itself; that is, by simply bundling and selling episodes together, the degree of between-episode cohesion is likely increased. Second, we can assume that the role of inter-episode theme plays a role in cohesion; that is, a sequence of thematically similar episodes is likely to be perceived as more cohesive compared to thematically different episodes.

In this article, we consider the case of a service bundle where cohesion between segments is assumed. Our research context is season subscriptions of themed bundled performing arts events; events are combined that have similar themes (genre, artist, composer, performer, and so forth) and that have similar temporal spacing between events. We do not explicitly test for, or compare levels of, cohesion in this study, but we investigate the presence of sequence effects within a previously uninvestigated area, mainly that of events that are temporally separate, thematically similar, and purposefully bundled. As mentioned above, past research as to what to expect in this case is mixed.

\section{Measuring Experiences}

The measurement of parts of an experience within sequence varies widely in past literature, that is, what is actually measured and when it is measured differ drastically. Earlier work focused on pain and discomfort in which participants were asked in real-time to rate their pain level; afterwards, participants were asked to summarize their overall experiences (Redelmeier and Kahneman, 1996). Other studies experimentally altered the sequence of discomfort (Ariely, 1998), service levels (Ariely and Zauberman, 2003), or extended uncomfortable end states (Kahneman et al., 1993) and then asked for 
overall evaluations of the experience in terms of pain, discomfort, satisfaction, happiness, or a choice between options.

All of the above measures can be considered a measure of utility; however, the timing of when evaluations are taken determines the type of utility. Kahneman et al. (1997) make a case that sequence effects are largely found in remembered utility or retrospective evaluations, for it is in our recollection of a sequence that we tend to rely on gestalt characteristics. They argue that in order to reveal these effects, researchers should also capture experienced utility or real-time evaluations. However, Soman (2003) found that different effects were emphasized depending on when-before or after the experience-the evaluation was requested. In the context of a "goal-oriented service" in which the customer hoped to arrive at some state at the end of the service (e.g., transportation services), Soman (2003) found that when participants were asked for a predicted utility or prospective evaluation, they overemphasized early delays. However, when participants were asked for a retrospective evaluation after the service was complete, they overemphasized late delays. This provides support that sequence effects can be found using predicted utility, and that the preference for different effects might be different for predicted measures than from remembered measures. Similarly, research on anticipation (e.g., Loewenstein, 1987) suggests that sequencing can alter predicted utility; under some conditions, participants would prefer to delay good things, that is, the utility of a future experience increases if there is time to savor the anticipation of the event.

A practical difficulty in investigating sequence effects in service bundles is appropriately measuring utility for each event. As we see in the previous paragraph, evaluations of an experience could happen prospectively, in real-time, or retrospectively. If service designers hope to implement sequence effects into the design of their experience, multi-episodic or otherwise, they will likely have to first rely on and determine an expected utility, that is, prospectively speculate on how their customers will evaluate an episode. For example, a teacher planning learning activities for an eight-week course will have to use experience and expert knowledge to predict how students will respond to and enjoy different activities. Such planning will be even more complex if she has never taught this specific course, these specific students, or used the specific activities before. The teacher will have to rely on a predicted utility in order to plan a schedule of activities.

We could define utility of an event as the perceived value of the event minus the cost. When cost is lower than value, there is positive utility; if value is lower than price, there is disutility. An event scheduler must price an event so that revenue is maximized. In order to do this, the scheduler has to have an idea of demand for the event and how demand may change at different price points. The 
rational economic model states that customers will buy if they predict that their utility for the event will be positive. It might be the case that customers' experienced or remembered utility is not positive for any given event, but by purchasing the tickets, they must have had a predictive utility that was positive. The profit-maximizing venue will not host or price an event for which average predictive utility will be negative. Therefore, in this study, we assumed that all episodes have a positive predicted utility and we deal exclusively in the realm of positive predicted utilities. Similarly, when we refer to peak events, we mean the events with highest positive utility as opposed to the negative utility sometimes used in other sequence research. Some of the previous gestalt characteristics research is in the context of pain and so uses only negative measures in which the most painful segment is considered the "peak" pain (Kahneman et al., 1993; Redelmeier and Kahneman, 1996). In contrast, we consider our "peak" event the one that had the highest positive utility.

In the case of a service bundle, customers decide their predicted utility of the entire package by calculating the predicted utilities for the individual parts of the bundle. It may be the case that a few items in the bundle have high utility, and so the excess is spread to the other parts in order to make them palatable. If there is not enough excess utility to spread out to all potential disutility parts, the customer will not purchase the bundle, but will instead buy individual parts. In fact, the behavior of the nonbundle purchasers gives us an indication of which events have higher value on average across the set of events. For example, if a bundle is made up of five events and the fifth element has twice the ticket sales of the others, we can assume that it has higher expected value than the other four. Since the bundle ticket purchasers have bought tickets to all five of the events, it was the behavior of nonbundle purchasers that indicated which events had higher predicted value.

Hence, the service scheduler can evaluate the expected utility of each event in a bundle, in comparison to the other events in the bundle-or across all offerings-with nothing more than an understanding of demand for each event, or by looking at archival data of past ticket sales. This approach is simpler than the more complex discrete choice models used in other service design research, but may be easier to implement in practice if the events are sold both as a bundle and individually, such as sporting and performing arts events and other services that are delivered in sequence.

Admittedly, the weakness in this approach is the use of predicted utility as opposed to experienced or remembered utility. In considering initial purchase, predicted utility is an appropriate measure, as it safely can be used to predict if a customer will buy a service bundle. Nearly all discrete choice models used to indicate utility of specific elements of a product use predictive utility. In 
considering repurchase or retention of customers, remembered utility is likely a better measure, since a customer considering repurchasing a bundle will consider his or her memory (remembered utility) of the past sequence as an aspect of deciding to repurchase the next bundle. In addition to the memory of the past sequence, customers likely will use the predicted utility of the next sequence in deciding to repurchase a bundle. Ideal in predicting repurchase behavior would be to have a remembered utility measurement of the past bundle and a predicted utility of the future bundle. However, remembered (or even experienced) utility is not easily captured by service providers; it requires customer feedback about each element of the bundle after the conclusion of the bundle and ideally at the time of decision to repurchase. However, as explained previously, predicted utility is more easily captured in archival ticket sales data. Although not ideal, in our study, we use the predicted utility measure for both the past sequence and the future sequence, in large part to determine if it was useful to do so. Since our model is the first of its kind to attempt to use archival data to find sequence effects, we believe that it is an acceptable first step in the application of service bundle sequence effect scheduling. Both our hypotheses and the discussion of our results will be considered in light of predicted utility having been shown to be different than remembered utility, and we will conjecture possible differences future researchers might find with ideal data in hand.

\section{Theory and Hypotheses}

The decision to repurchase a repeating service bundle is based on the evaluation of the previous experience with the service (e.g., LaBarbera and Mazursky, 1983; Rust and Zahorik, 1993) and prospective evaluation of the future bundle. The evaluation of a product or service is in large part a function of evaluating multiple attributes that make up the offering (Gensch and Recker, 1979).

The random utility theory and the corresponding discrete choice modeling approach suggest the utility of possible selection is based on the characteristics of individual decision-makers (e.g., customer) and the attributes (e.g., price, quality, and brand name) of the alternatives (McFadden, 1980; Luce, 1959; Ben- Akiva and Lerman, 1985). In particular, research suggests that after acquiring information and learning about possible alternatives, decision-makers define a set of determinant attributes to use to compare and evaluate alternatives. After comparing available alternatives with respect to each attribute, decision-makers eliminate some alternatives and form a final choice set containing a few alternatives. They then form impressions of each alternative's position on the determinant attributes, value these attribute positions with one another (i.e., make tradeoffs), and combine the attribute 
information to form overall impressions of each alternative. The random utility theory then assumes that an individual's choice behavior is generated by maximization of preferences or utility.

The typical customer choice model (Ben-Akiva and Lerman, 1985) can be expressed as:

(1)

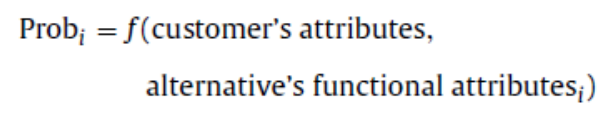

In other words, the probability of choosing alternative $i$ is a function of the customer's attributes and the alternative's (or product and service functional) attributes (Ben-Akiva and Lerman, 1985). In this manner, service design researchers have shown that service providers can gain valuable information about what type of customers are drawn to their offerings and what attributes these customers prefer (e.g., Verma et al., 1999, 2001). Our primary interest in this study is in knowing if sequence effects are used by customers as a functional attribute in repurchase decisions of discrete service bundles. As noted previously, the behavioral literature is mixed concerning whether or not gestalt characteristics are important functional attribute for a bundle of discrete events that span an elapsed period of time. The non-continuous nature suggests that the sequence effects should not matter, but the cohesion of the events within the same bundle suggests that they may. In order to test for the presence of sequence effects, we propose a nested-model comparison for which earlier models do not include gestalt characteristics of the bundle, while later models do. We propose, as a null hypothesis, that there is no difference in model fit characteristics (e.g., goodness of fit, prediction) between nested models. Because of the assumed cohesion among events in a themed bundle, we suggest the alternative hypothesis as follows:

H1. The accuracy of service bundle repurchase predictive models improve significantly by including sequence effects, in addition to customer attributes and bundle features as independent variables.

This first hypothesis is our primary concern in this article. Simply put, we hope to find that the sequence of discrete service events matter in a customer's decision whether to repurchase. We investigate this hypothesis using past and future sequence attributes. Guided by the past literature and specific contextual attributes of our study-discrete, time-separated, theme-bundled events for which utility is measured with prospective evaluation-we suggest several other secondary hypotheses.

Ariely and Carmon suggested that "frequent recent exposure. . to similar experiences" is likely to lessen the peak effect in any given sequence, since a peak in one experience may not be very salient compared with a larger peak in a previous sequence (2000, p. 194). This observation has intuitive 
appeal, and we hypothesize that as customers experience the same bundle repeatedly, a peak is less salient since it may not be as extreme as a peak in an earlier experience of the bundle. Customers new to a bundle should then be more influenced by a peak since they have fewer past experiences by which to compare it.

$\mathbf{H 2 a}$. The relative weight of peak effects on repurchase is reduced as customers become more familiar with a service bundle.

Soman (2003) found that when participants used prospective evaluation, they preferred a sequence for which a peak disutility (negative) was placed earlier in the sequence as opposed to later; the participants preferred to experience the anticipated dreaded event as quickly as possible. As stated earlier, we assume only positive utility and consider the peak event the highest positive utility event in a bundle. With a prospective evaluation of a peak event, customers would experience anticipation as opposed to dread, which may change preferences. One argument would suggest that with a prospective evaluation, customers are unlikely to want to maximize the end state by preferring a late-peak placement, but would instead prefer an earlier peak in order to capture the value of the peak event as early as possible. Another argument would be that customers want to linger in the anticipatory state and therefor prefer a late-peak placement. Another consideration is the sequence under consideration; in our study, we consider both the most recent sequence and the future sequence. At the time of repurchase a sequence has just been completed and could be used to evaluate future sequences, and the future sequence has been presented to the customers for consideration. Although we use a prospective, demand-driven evaluation of events for both past and future sequences, only the future sequence evaluation is truly prospective, since the past sequence had been experienced. We then follow Soman's (2003) research that suggested preferences for peak placement change when the evaluation time was different:

H2b. The relative weight for the placement of a peak event for repurchase is different for past and future service bundles.

The above hypothesis gives no direction as to how we believe the placement of peaks differs because there is no strong research to support one hypothesis over another. However, the majority of sequence research suggests that the end state heavily influences retrospective evaluation. We predict that as the utility of the last event of the past sequence increases, its effect will remain salient in the customer's mind at the time of repurchase and will result in a higher overall probability of repurchase: 
H2c. Customers' likelihood to repurchase increases as the last event's utility increases in the past service bundle.

Conversely, we have no reason to believe that the utility of the last event in a future bundle should influence the evaluation of that bundle. Soman's research (2003) suggested that it is in the experiencing rather than the prediction of the last event that makes its timing significant in influencing overall evaluations.

H2d. Customers' likelihood to repurchase is not influenced by the last event's utility in the future service bundle.

Finally, Chase and Dasu (2001) suggested that as a sequence improves over time, the feeling of loss is avoided and customer evaluations improve; however, Ariely and Zauberman (2003) found that as the events of a sequence become more discrete, trend effects are less important to evaluations. As discussed earlier, our study is different than past research since we anticipated a level of cohesion due to thematic bundling that was previously not considered. However, it is beyond the scope of this research to consider how different levels of cohesion of this sort will influence sequence effects. For this reason, we follow previous research in our expectations for trend effects:

H2e. Repurchase probabilities of a service bundle are not influenced by the trend of the event's utility over time.

\section{Research Design}

In order to test the proposed hypotheses, we estimate a series of econometric models that predict the probability that a customer who had purchased a given service bundle them for a given time period would again purchase a repeating bundle theme the subsequent time period. (We refer a time period as a "season".)

Specifically, for the set of customers $C$ who bought bundle $\mathrm{j}$ season $\mathrm{t}$, we are interested in predicting whether or not each customer will buy bundle $\mathrm{j}$ season $t+1$, that is, the same bundle the subsequent season (as explained in the following section, the same bundle does not imply the exact same events, but instead the same bundle theme). The unit of analysis is individual customers who purchased a given bundle of the previous season, and our dependent variable is binomial: 1 , if the customer purchased the same bundle the subsequent year; 0 , if they did not. Since our dependent variable is binary, we have chosen to model the data using logistic regression. Our econometric model uses the following form, 
(2)

$\ln \left(\frac{P\left(Y_{c j t+1}=1\right)}{1-P\left(Y_{c j t+1}=1\right)}\right)=\beta X+\varepsilon \quad \mid Y_{c j t}=1$

where $Y_{\mathrm{cjt+1}}=1$ represents a repurchase of bundle $\mathrm{j}$ in season $\mathrm{t}+1$ (the next season's bundle) by customer $\mathrm{c}, \mathrm{X}$ is a vector of predictors, $\beta$ is the vector of coefficients including an intercept, and $\varepsilon$ are the errors. This model is estimated across all customers i who purchased bundle $\mathrm{j}$ in season $\mathrm{t}$. The model predicts the log-odds of repurchase given the set of independent variables using a maximum likelihood estimator, assuming the distribution of errors follows a logit distribution. The actual model is estimated using fixed effects for seasons and robust standard errors (Huber-White) grouped on each customer. Described in more detail below, the independent variables include customer characteristics, service attributes, and sequence-related variables.

\section{Data Description}

To test the proposed hypotheses, we used a multi-year subscription ticket purchase database for an internationally renowned performing arts venue. This concert venue houses five concert halls that can be used simultaneously. The venue hosts approximately 300 events per year and offers over 40 different subscriptions to its customers. The database includes 6 seasons of ticket sales data including over 1 million individual ticket sale transactions for more than 2400 events purchased by over 50,000 unique customers. The database includes the date and time of the ticket purchase, the price paid, membership status of the customer during time of purchase, general seating category (based on price category), and whether the ticket was purchased as a part of a subscription. Additionally, we are given details about all the events such as the date and time of the event, the genre of the event (out of 16 possible genres), and the specific concert hall used for the event. Finally, we have limited customerspecific information that is optional when creating an account with the venue: gender, title, degree held, postal code, and so forth.

The subscriptions offered by the venue are bundle themes offered year after year. Most bundles are based either on a certain genre or are specific to a particular ensemble. Themes based on genre alone include Jazz, Classical Symphony, Music and Film, Piano, and Children's Music. Other themes include Rising Stars, International Orchestras, International Quartets, Beethoven, and Original Compositions.

Bundle themes repeat each season; however, unique bundles are not identical replication of the previous year's offerings, but instead consist of different performances that match the theme. The 
concert venue has historically found that patron loyalty is specific to bundle theme, i.e., patrons that repurchase subscription year after year tend to repurchase within the same bundle theme. The repeating nature of the thematic subscriptions allowed us to link bundles year to year to determine if a given customer repurchased the same bundle theme the next season. In the 6 years of data, we found 41 bundle themes that repeat for all 6 seasons for a total of 246 unique bundles. There were other bundle themes that did not repeat all 6 seasons, but for reasons forthcoming, they were left out of the analysis.

\section{Customer Specific Variables}

In predicting repurchase, we consider three general sets of variables: first, customer-specific attributes, second, bundle-specific attributes, and finally sequence specific variables. We are not primarily interested in customer- and bundle-specific attributes, but they are included in the model to act as control variables. Additionally, our main hypothesis states that by including sequence attributes, our model should improve; therefore, we compare models that included sequence variables with those that did not.

Customer-specific attributes include gender, seating category of tickets (seat placement), number of bundles purchased (for a given bundle, not across all bundles), total number of unique bundles purchased for the season, days from purchase date to first event in the bundle (measure of how early a bundle was purchased), and membership status. Since we are predicting the purchase of bundle $\mathrm{j}$ season $t+1$, we derive the above-mentioned variables from ticket sales at the end of season $t$, that is, at the repurchase decision time. Additionally, we created a variable to determine the customer's experience or loyalty with the bundle theme. We classify customers into four groups and subsequently predict that the groups can be thought of as ordinal in their likelihood to repurchase. The first group consists of those customers who have purchased the given subscription bundle theme for the past three seasons; we name these customers Longtime Loyal. The second group consists of customers who have purchased a given bundle theme for the past two seasons, but not the past three seasons; we name these Upcoming Loyal since their recent behavior suggested they are becoming more loyal. The third group we name Fickle and is made up of customers who have purchased a given bundle theme one season ago and three seasons ago, but not two seasons ago. They are fickle because they are not consistent in repurchasing. Finally, the last group is called New and is made up of those customers who have purchased the bundle theme for only one season. 
By calculating the loyalty variable, we set a limit on the data that can be used in the model because the fourth season $(t=4)$ is the earliest we can start to predict repurchase. For $t=4, t-3$ is season 1 , season $t-2$ is season 2 , and season $t-1$ is season 3 . Additionally, for the fifth and sixth seasons, we use the previous three seasons to determine loyalty status (i.e., for $t=5$, loyalty is based on seasons 4, 3, and 2; for $t=6$ loyalty is based on seasons 5,4 , and 3 ). With this restriction, we model repurchase predictions for seasons 4,5 , and 6 , which have 40 bundle themes. There were an additional four more bundle themes that the venue initiated in season 2, for which we only modeled seasons 5 and 6 , giving us a total of 128 unique bundles ( 40 bundle themes with 3 seasons +4 bundle themes with 2 seasons). Within those 128 unique bundles, we found a total sample size of $n=31,816$ customers who had purchased a bundle the previous season. Given the total size of the dataset and the resulting sample size for the model, we were satisfied with reducing the data in order to derive the loyalty variables.

In our final model estimation, we excluded a random $10 \%$ of the observations used to validate the accuracy of the model. Further, we identified and excluded one outlier observation that proved to be a significant influence on the model estimation. Table 1 shows a summary of the customer-specific variables.

\section{Bundle-Specific Variables}

Both marketing and operations management researchers consider the product/service mix to be an important aspect of customer satisfaction, perception, intention, and subsequent choice processing. The product/service mix is the set of attributes for a given product and service; for example, a hotel property might include an exercise facility, a pool, a restaurant, wireless Internet, and concierge service; a credit card might have fraud protection, online account access, automatic bill pay, and cash back rewards; a car might have good gas mileage, five cup holders, a moon roof, and Bluetooth capability. Service providers have to choose what attributes to include in their offerings in order to entice the right customer to purchase. In the case of the concert venue, management must create bundles of subscriptions that include attributes such as the number of events in the bundle, the genre mix of the events, the percent of events on a weekend (Friday-Sunday) vs. a weekday, and the percentage of nonmatinee events vs. matinee (before 5:00 p.m.). Adding to the list of bundle-specific variables, we include a measure of total bundle utility calculated as the sum of all the individual event utilities. Event utility calculations are described in the next section. 
Table 1

Descriptive statistics of customer attributes variables.

\begin{tabular}{|c|c|c|c|}
\hline & Non-repurchasers & Repurchasers & All customers \\
\hline Days from purchase to first event ${ }^{*}$ & 115.72 & 130.70 & 126.41 \\
\hline Bundles purchased (for bundle $j$ ) & 1.74 & 1.76 & 1.75 \\
\hline Unique bundles purchased" (in season $t$ ) & 1.94 & 2.14 & 2.08 \\
\hline \multicolumn{4}{|l|}{ Gender } \\
\hline Male & $38 \%$ & $41 \%$ & $40 \%$ \\
\hline Female & $8 \%$ & $7 \%$ & $7 \%$ \\
\hline Unknown & $55 \%$ & $52 \%$ & $53 \%$ \\
\hline Member & $20 \%$ & $10 \%$ & $13 \%$ \\
\hline Non-member & $80 \%$ & $90 \%$ & $87 \%$ \\
\hline \multicolumn{4}{|l|}{ Experience } \\
\hline Longtime loyal & $24 \%$ & $69 \%$ & $56 \%$ \\
\hline Upcoming loyal & $4 \%$ & $2 \%$ & $2 \%$ \\
\hline Fickle & $16 \%$ & $13 \%$ & $14 \%$ \\
\hline New & $57 \%$ & $17 \%$ & $28 \%$ \\
\hline Seating category $1^{*}$ & $35 \%$ & $27 \%$ & $29 \%$ \\
\hline Seating category $2 *$ & $16 \%$ & $17 \%$ & $17 \%$ \\
\hline Seating category 3 & $21 \%$ & $18 \%$ & $19 \%$ \\
\hline Seating category $4 "$ & $17 \%$ & $17 \%$ & $17 \%$ \\
\hline Seating category $5 *$ & $12 \%$ & $12 \%$ & $12 \%$ \\
\hline Seating category $9^{* *}$ & $0.3 \%$ & $0.4 \%$ & $0.3 \%$ \\
\hline Seating category $6 "$ & $11 \%$ & $12 \%$ & $12 \%$ \\
\hline Seating category $7^{*}$ & $5 \%$ & $5 \%$ & $5 \%$ \\
\hline Seating category $8^{* *}$ & $1.2 \%$ & $2.2 \%$ & $1.9 \%$ \\
\hline$n$ & 9108 & 22,708 & 31,816 \\
\hline
\end{tabular}

(3)

total bundle utility ${ }_{b}=\sum_{\text {events } \in \text { bundle } b}$ Utility $_{e}$

This variable can be thought of as a measure of the total number of events within the bundle as well as the relative popularity of the subscription as a whole. These bundle attribute variables can be determined for both the past experienced season and the upcoming future season, that is, for season $t$ and season $t+1$.

Determining the Utility of an Event

As discussed earlier, as a measure for individual event utility, we rely on a prospective measure of utility largely determined by fulfilled demand. Specifically we use a measure of both seat occupancy and ticket price: Revenue per Available Seat (REVPAS). REVPAS is calculated by dividing the total revenue for each event by the total number of available seats for the event.

(4)

ticket $_{\text {price }}$ ce $=$ the price that customer $c$ paid for evente.

(5)

available seats $_{e}=$ the number of available seats for event $e$. 
(6)

$$
\text { Utility }_{e}=\text { REVPAS }_{e}=\frac{\sum_{c} \text { ticket price }_{c e}}{\text { available seats }_{e}}
$$

REVPAS is adapted from the revenue management field for which some measure of revenue per available unit is maximized. For example, revenue per available room (REVPAR) is used widely in the hotel industry and has been shown to be highly correlated to customer satisfaction (Davidson et al., 2001; Davidson, 2003), service quality (Kimes, 2001, 1999), and brand loyalty (Kim et al., 2003; Kim and Kim, 2005). Consumers are often uncertain about the quality of a hotel property (as they are with performing arts events) and use price as a signal for expected quality. Consistently demanding higher prices and filling more rooms suggests that hotels with high REVPAR are able to deliver on the expectation set by the price signal, resulting in repeat business, loyalty, and positive word of mouth. Not unlike hotel brands that have proven their value, some performers or performances can demand higher prices and fill more seats because they provide a higher valued event.

Unfortunately, our data does not provide us with the means to derive an individual customer level measure, and so we chose to test our hypotheses with aggregate measures. Certainly this is a weakness of our model from an individual customer's perspective and is not ideal in deriving a choice model; however, from the standpoint of the service provider, an aggregate measure is needed to implement a scheduling methodology based on our results. Event schedulers forecast aggregate demand for each event and set prices accordingly. The forecasts are based on a combination of past attendance data and industry trend knowledge. Because the forecasts are derived from the same data we use in deriving event utility, they can be used to sequence the events according to the results of our model. With this early research we are content with assuming that the aggregate measure reflects a fair starting point in investigating the presence of sequence effects in our context. Table 2 shows descriptive statistics for bundle variables.

\section{Sequence Variables}

The sequence variables are of primary interest in this model, as they are used to test our proposed hypotheses. We identify the event with the highest utility within a subscription and captured its utility as the peak event utility. To consider the trend of the sequence of events, we calculate the utility slope for the line fit in ordinary least squares regression through event utilities and the number of days from the beginning of the bundle. 
Table 2

Descriptive statistics for bundle attributes variables.

\begin{tabular}{lcc}
\hline Total subscription bundles considered & $\begin{array}{l}128 \\
\text { Average }\end{array}$ & $\begin{array}{c}\text { Standard } \\
\text { deviation }\end{array}$ \\
\hline Percentage of events across all bundles $^{\mathrm{a}}$ & & \\
$\quad$ Ancient music & $3.2 \%$ & $15 \%$ \\
New music & $4.2 \%$ & $19 \%$ \\
Jazz & $2.3 \%$ & $15 \%$ \\
World music & $4.7 \%$ & $21 \%$ \\
Children's music & $18.8 \%$ & $39 \%$ \\
Literature & $2.3 \%$ & $15 \%$ \\
Organ music & $2.3 \%$ & $14 \%$ \\
Piano music & $7.7 \%$ & $26 \%$ \\
Chamber music & $23.4 \%$ & $41 \%$ \\
Vocals & $6.7 \%$ & $21 \%$ \\
Choral music & $0.1 \%$ & $1 \%$ \\
Orchestra & $21.3 \%$ & $37 \%$ \\
Film & $3.0 \%$ & $15 \%$ \\
Number of genres in bundle & 1.33 & 0.74 \\
Percentage of events on weekends & $52 \%$ & $33 \%$ \\
Percentage of events in the evening & $80 \%$ & $37 \%$ \\
Total bundle utility & 93.23 & 72 \\
\hline
\end{tabular}

a Percentage of events within each genre was calculated for each bundle; the average and standard deviations across all bundles are reported.

(7)

Slope of bundle $e_{b}=\frac{\sum_{e \in E_{b}}\left(\text { utility }_{e}-\text { avg_utility }_{b}\right)\left(\text { days from first } t_{e}-\text { avg_days from first }_{b}\right)}{\sum_{e \in E_{b}}\left(\text { utility } \text { frov_utility }_{b}\right)^{2}}$

Table 3

Descriptive statistics of sequence attributes.

\begin{tabular}{lll}
\hline & Mean & Standard deviation \\
\hline Peak event utility & 19.26 & 13.9 \\
End event utility & 14.49 & 10 \\
Slope of sequence & 0.0011 & 0.02 \\
Days from peak event to end event & 104.39 & 77.4 \\
Days from first event to peak event & 108.96 & 79.92 \\
& & \\
& Count of subscriptions \\
\cline { 2 - 3 } & \multicolumn{2}{l}{} \\
& Days from & Days from first \\
& peak to end & to peak \\
\hline 0 days & 18 & 27 \\
$1-50$ days & 20 & 14 \\
$50-100$ days & 18 & 28 \\
$100-150$ days & 23 & 22 \\
$150-200$ days & 20 & 18 \\
$200-250$ days & 29 & 128 \\
Total subscription bundles & 128 & \\
\hline
\end{tabular}

To consider the impact of the final state, we capture the last event's utility. As mentioned earlier, we consider both the most recent past season and the next season, that is, season $t$ and $t+1$. 
Customers make their repurchase decisions between the last event of the previous season and the first event of the next season, so both the number of days from the peak event to the last event for the previous season $(t)$ and the number of days from the first event to the peak event in the upcoming season $(t+1)$ are used as measures of the placement of the peak event relative to the event closest to the time of the decision. In both cases, as this measure reached 0 , a peak is as close as possible to a purchase decision (Table 3).

\section{Results}

Due to the large number of variables available to predict repurchase, we chose to create three models nesting the three main variables types: customer specific, bundle specific, and sequence specific. We use nested model comparisons to determine if adding additional variables leads to an improved fit. The following three models were estimated:

Model 1: Customer-specific variables.

Model 2: Customer-specific and bundle-specific variables.

Model 3: Customer-specific, bundle-specific, and sequence variables.

As discussed earlier, at the time of the repurchase decision, customers may use both their recently experienced past season perspective and the future season perspective, that is, when deciding to purchase the next season, customers can consider what they just experienced and what is offered in the next season. Therefore, bundle-specific and sequence variables can be considered for both the past season and the future season. With this in mind, we estimated Model 2 using both season perspectives separately. Since bundles are thematic in nature, the attributes from one season to the next are highly correlated, raising concerns of multicolinearity. Additional models were estimated that included both perspectives together; however, these combined models had high variance inflation factors and coefficients that changed signs (both signs of high multicolinearity). For this reason, we did not report combined season perspective models; the only exception is that, in Model 3, we estimated a model that included future bundle-specific and sequence variables and past sequence variables (not including past peaks; again, they are highly correlated with future peaks).

Because of the panel nature of our data (same customers over several time periods), we approached the estimation with a multilevel estimator: First, we included a fixed effect for the season by adding two dummy variables for seasons 4 and 5 . This controlled for unobserved homogeneity within each season. To control for unobserved homogeneity within customers, we estimated the model by 
adjusting for standard errors using Huber White Robust (sandwich) errors clustered on each customer ID.

The results of the models are shown in Table 4. Recall that the customer and the bundle attributes were not the primary concern for this study. We were interested in Models 1 and 2 primarily in comparison to Model 3. Therefore, we will only briefly discuss their results. The customer attribute model showed the following results:

- The coefficient for the number of days from purchase to the first event is positive, indicating that customers are more likely to repurchase if they buy their tickets early.

- As customers purchase more number of subscriptions, both within the bundle and across all bundles within the season, the more likely the customer is to repurchase the following season. These variables are not significant in Model 1, but become significant as additional variables are added.

- Customers that are also members are more likely to repurchase than nonmembers.

- Compared to New customers, Longtime Loyal, Upcoming Loyal, and Fickle customers are all more likely to repurchase. Surprisingly, Fickle customers are more likely to repurchase than Upcoming Loyal customers.

- Customers who purchase higher priced seats (seat categories) have a higher likelihood of repurchase. 
Table 4

Logistic regression results.

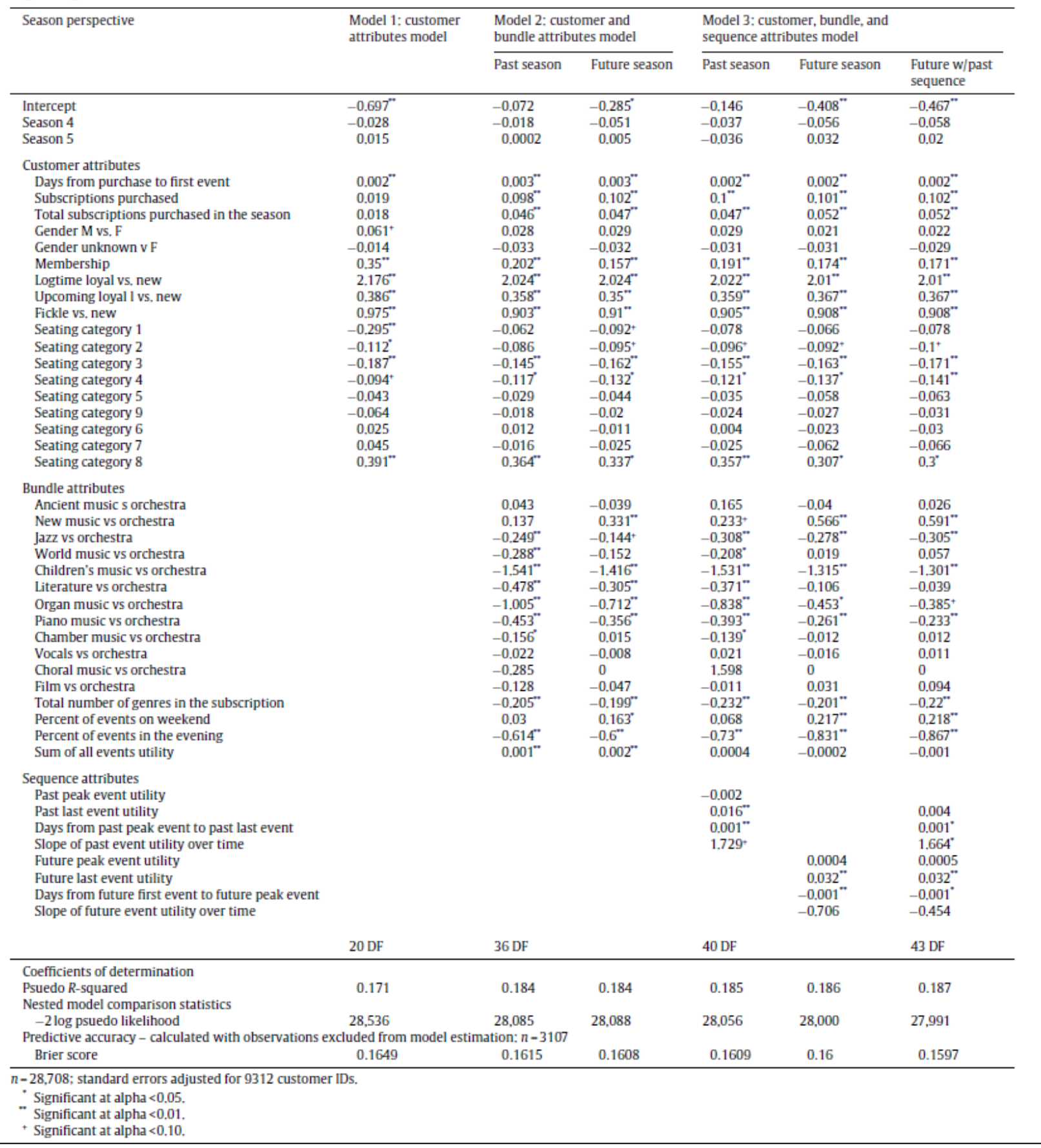


Table 5

Likelihood ratio test for nested model comparison.

\begin{tabular}{|c|c|c|c|c|c|c|}
\hline \multicolumn{7}{|c|}{$\begin{array}{l}\left(-2 \log \text { likelihood }{ }_{\text {model } 1}\right)-\left(-2 \log \text { likelihood }_{\text {model } 2}\right) \sim \chi^{2} \\
\text { df }-\mathrm{df}_{\text {model } 2}-\mathrm{df}_{\text {model } 1}\end{array}$} \\
\hline & \multirow[t]{2}{*}{ Model 1: customer attributes model } & \multicolumn{2}{|c|}{$\begin{array}{l}\text { Model 2: customer and } \\
\text { bundle attributes model }\end{array}$} & \multicolumn{3}{|c|}{$\begin{array}{l}\text { Model 3: customer, bundle, and } \\
\text { sequence attributes model }\end{array}$} \\
\hline & & Past Season & Future Season & Past Season & Future Season & Future w/past Sequence \\
\hline $\begin{array}{l}-2 \text { log likelihood } \\
\text { DF } \\
\text { Likelihood ratio } \\
\text { Degrees of freedon } \\
\text { Pr }>\text { ChiSq }\end{array}$ & $\begin{array}{l}28,536 \\
20\end{array}$ & $\begin{array}{l}28,085 \\
36 \\
451 \\
16 \\
<0,001^{*}\end{array}$ & $\begin{array}{l}28,088 \\
36 \\
448 \\
16 \\
<0,001^{*}\end{array}$ & $\begin{array}{l}28,056 \\
40 \\
30 \\
4 \\
<0,001^{-*}\end{array}$ & $\begin{array}{l}28,000 \\
40 \\
88 \\
4 \\
<0,001^{-*}\end{array}$ & $\begin{array}{l}27,991 \\
43 \\
9 \\
3 \\
0,027^{m+\cdots}\end{array}$ \\
\hline \multicolumn{7}{|c|}{$\begin{array}{l}\text { Comparing Model } 2 \text { with Model } 1 \text { within same season perspective. } \\
\text { Comparing Model } 3 \text { with Model } 2 \text { within same season perspective. } \\
\text { Compared to Model } 3 \text { future season perspective. }\end{array}$} \\
\hline \multicolumn{7}{|c|}{$\begin{array}{l}\text { ( }-2 \log \text { likelihood } \text { model cmplete })-\left(-2 \log \text { likelihood }_{\text {model less one variable }}\right) \sim \chi^{2} \\
\text { df }-1\end{array}$} \\
\hline Variable & & \multicolumn{2}{|c|}{$x^{2}$} & \multicolumn{2}{|l|}{$p>\chi^{2}$} & \\
\hline Past last event utili & & \multicolumn{2}{|c|}{1.61} & \multicolumn{2}{|l|}{0.2052} & \\
\hline Days from past pea & ent to past last event & \multicolumn{2}{|c|}{17.99} & \multicolumn{2}{|l|}{$<0,0001$} & \\
\hline Slope of past event & ty over time & \multicolumn{2}{|c|}{0.25} & \multicolumn{2}{|l|}{0,6177} & \\
\hline Future peak event & & \multicolumn{2}{|c|}{0.02} & \multicolumn{2}{|l|}{0.898} & \\
\hline Future last event u & & \multirow{2}{*}{\multicolumn{2}{|c|}{$\begin{array}{r}135.83 \\
15.29\end{array}$}} & \multicolumn{2}{|l|}{$<0,001$} & \\
\hline Days from Future f & vent to future peak event & & & \multicolumn{2}{|l|}{$<0,001$} & \\
\hline \multicolumn{2}{|c|}{ Slope of future event utility over time } & \multicolumn{2}{|c|}{$\begin{array}{c}15.29 \\
2.8\end{array}$} & \multicolumn{2}{|l|}{0.0943} & \\
\hline
\end{tabular}

The customer attributes in the second and third models retained their sign and general magnitude. The new variables introduced in the customer and bundle model showed the following results:

- Compared to Orchestra, nearly all genres have negative estimated coefficients, indicating lower likelihood of repurchase.

- As the number of genres in a bundle increase, repurchase likelihood decreases, indicating that, on average, mixed-genre bundles do not fare as well as single-genre bundles.

- As the percentage of weekend events in a bundle increases, repurchase is more likely.

- As the percentage of evening events in a bundle increases, repurchase is less likely.

- Total bundle utility (sum of all event utility) is significant and positive in Model 2, indicating that, as total bundle utility increases, repurchase likelihood increases. However, when the sequence variables are introduced in Model 3, the total bundle utility variable loses significance, indicating that total bundle utility can be better explained with the sequence variables. 


\section{Hypotheses Testing and Discussion}

\section{Hypothesis 1}

Our primary hypothesis - by including sequence variables, the predictive model improves-can be tested using nested model comparison statistics. Using the changes in -2 pseudo log likelihood and the difference in degrees of freedom across the models, we created a hypothesis test to determine if the added variables in the model significantly added to the fit of the model. A decrease in -2 pseudo log likelihood indicates an improved goodness of fit.

Table 5 shows that, comparing Model 2 to Model 1, there is evidence that the added bundlespecific variables improved the model $(p<0.00001)$. Similarly, going from Model 2 to Model 3 (within season perspective, i.e. past and future season), there is evidence that the sequence variables also improved the model's fit significantly $(p<0.00001)$. Finally, adding the past season's sequence variables to the Model 3 future season also improved the model's fit $(p=0.027)$. These conclusions indicate that the sequence variables, as a whole, significantly improve the fit statistics of the model, providing support for Hypothesis 1.

We can take a similar approach to determine if specific variables alone improve the fit of the model. In order to do this, we compared a complete model with a model fit in which one term had been dropped. Terms were dropped one at a time, in turn, and the same chi-squared hypothesis test performed above (with degree of freedom $=1$ ) was used to consider the usefulness of each variable to the fit of the model. Table 6 shows the results of individual sequence variable influence on the log likelihood of the final model.

The results show that not all of the sequence variables contributed to the fit of the model. Only the days from past peak event to the past last event, future last event utility, and days from future first event to future peak event significantly improved the model fit alone. These same variables also had estimated coefficients that were significantly different than 0 , as shown in Table 4. A similar approach was taken with identical results using Bayesian Information Criterion (BIC) comparisons between the complete model and models with one variable missing. This test is appropriate with models with a large sample size and a large number of estimators, and can be used as a supplement to and support for standard significance test results from coefficient estimates (Millar, 2006). These results suggest that, individually, the two peak placement variables and the last event utility were most important among the sequence variables in our dataset, and that they significantly contributed to the fit of the repurchase model. 
A similar test could be performed to compare if the R-squared improvement between nested models was significant using an $\mathrm{F}$ test (Cohen, 1968). Table 7 presents the results of the change in Rsquared $\mathrm{F}$ test. The results show that even though the change in R-squared seemed small, they were all significant except for the addition of a past sequence variable to the future sequence variable Model 3. This provides additional support that the model's fit is improved as sequence variables are added.

In addition to model fit, we considered the models' abilities to accurately predict. The expected probabilities of repurchase for the excluded $10 \%$ were calculated and a Brier score was determined (the average of the squared difference between the prediction and the outcome). Brier scores ranged from 0 for a perfect prediction to 1 for a perfectly incorrect prediction, so a smaller score indicate an improved prediction. The scores for the three models improved across models within the season perspective, but only slightly (past season: $0.1649,0.1615$, and 0.1609 ; future season: $0.1649,0.1608,0.16$, and 0.1597 ). A logistic regression model predicts log odds that can be converted into probabilities; at some point, the probabilities must be converted into predictions. We calculated the probability of repurchase for all customers and classified those with $50 \%$ probability of repurchase as a repurchase and determine the percentage correctly classified, i.e. calculated a residual. Again, we saw a slight increase across models within the season perspective (past season: $76.65 \%$ and $76.70 \%$; future season: $76.55 \%, 76.70 \%$, and $76.85 \%)$.

Table 7

$R$-squared change $F$ test.

$\frac{\left(R_{\text {model } 12}^{2}-R_{\text {modee } 1}^{2}\right) /(\text { predictors }}{\left(1-h_{\text {mode } 2}^{2}-\text { predictors model } 1\right)}$

df1 - predictors ${ }_{\text {model } 2}-$ Predictors model $1_{1}$

df $2-n-$ predictors $_{\text {model } 2}-1$

\begin{tabular}{|c|c|c|c|c|c|c|}
\hline & \multirow[t]{2}{*}{ Model 1: customer attributes model } & \multicolumn{2}{|c|}{$\begin{array}{l}\text { Model 2: customer and } \\
\text { bundle attributes model }\end{array}$} & \multicolumn{3}{|c|}{$\begin{array}{l}\text { Model 3: customer, bundle, and } \\
\text { sequence attributes model }\end{array}$} \\
\hline & & Past season & Future season & Past season & Future season & Future w/past sequence \\
\hline Psuedo $R$-squared & 0.1707 & 0.1839 & 0.1838 & 0,1848 & 0,1864 & 0.1866 \\
\hline Change in $R$-squared & & 0.0132 & 0.0131 & 0.0009 & 0.0026 & 0.0002 \\
\hline F & & 28.96 & 28.74 & 7,91 & 22,90 & 2.35 \\
\hline df1 & & 16 & 16 & 4 & 4 & 4 \\
\hline df2 & & 28,671 & 28,671 & 28,667 & 28,667 & 28,668 \\
\hline$p$ & & $<0,001^{\circ}$ & $<0,001^{\circ}$ & $<0^{\circ}, 001^{*}$ & $<0.001^{*}$ & $0.09^{-\cdots}$ \\
\hline
\end{tabular}

- Comparing Model 2 with Model 1 within same season perspective,

- Comparing Model 3 with Model 2 within same season perspective.

-. Compared to Model 3 future season perspective.

The conclusions drawn from the previous paragraphs are that the sequence variables, and some individual variables alone, significantly improved the model's fit; however, the sequence variables were not likely to significantly improve predictive power. What this means from a modeling perspective is that the sequence variables could be considered good descriptive variables because some of the estimated coefficients were significant and could be used to describe the behavior of customers; 
however, they were poor predictive variables because they did not improve the ability of the model to predict. It is likely the case that Model 2 (nonsequence) is able to estimate fairly well the direction of a probability. With the inclusion of sequence variables in Model 3, the probabilities and model fit improved (got closer to $100 \%$ or $0 \%$ ), but the overall predictions did not change much. In this sense, the sequence variables are better able to describe how a customer decides, but not predict. From a theoretical standpoint, we were happy to derive from the model a better descriptive understanding of customer actions regardless if the predictive power fails to impress. Therefore, our model provided evidence to support hypothesis 1 , and even more specifically, it showed that sequence variables could significantly improve the descriptive power of a model.

\section{Hypothesis $2 a$}

Hypothesis 2a states that as customers become more experienced with a sequence, the peak effect will be less important. This has intuitive appeal and was introduced by Ariely and Zauberman (2000) as a reason why the peak effect was not found in some of their studies; mainly that, as customers have been through several rounds of an experience, an interexperience peak may not be as influential because they have experienced something just as salient or more in the past. With our initial models, we found that there was no support for peak effects; the peak event utility was not a significant variable in any model (past or future). However, to formally test this theory, we estimated two additional models with an additional variable considering the interaction effect between customer loyalty and future peak event utility-more specifically, we estimated a model using a variable with an interaction between longtime loyal customers and Future Peak Event Utility, and an additional model that included an interaction between new customers and Future Peak Event Utility. For support of our hypothesis and past literature, we expected the longtime loyal interaction variable to be insignificant. Instead, we found that the coefficient for this variable was positive and significant (coef. $=0.01, p<0.001$ ), indicating that for longtime loyal customers, a higher peak event utility for a future bundle made repurchase more likely. Similarly, we expected a variable that new customer interaction be positive, but instead we found the opposite (coef. $=-0.007$ neg., $p=0.003$ ). This means that as a peak event in future bundles increases in utility (controlling for total bundle utility), the likelihood of a new customer repurchasing decreases.

These two findings cannot be explained by past research and warrant additional future investigation. The retention of new customers is of particular interest to our data provider because it is important to the long-term viability of the venue. From discussions with the data provider, we learned 
that the longtime loyal customer segment had been shrinking in the past decade; the customers in this segment were made up of an aging demographic that had been loyal to the venue for decades, but were slowly stopping regular purchases due to age-related capabilities. New customers were not replacing loyal customers as readily as they had in the past and it seemed that their preferences differed. Our findings suggest that one difference between loyal and new customers may be in how they perceived peak events in an offering. While a high peak event might entice a longtime loyal customer to stick to the bundle for one more year, it seemed to be a turn off to the new customer. It appears that new customers are skeptical of the value of highly leveraged bundles, that is, those bundles for which a peak event is much higher than the other events. The new customer segment appears to form higher prospective evaluations on bundles that have flatter profiles, that is, less variability. Different from the older longtime loyal segment, the younger segment has been accustomed to buying only parts of their entertainment (e.g., iTunes makes it possible to buy a single song from any album). This behavior implies that, rather than being enticed to purchase the entire future bundle as a peak event becomes more predictable and prospectively salient, a younger segment might purchase only the peak event and pass on the remaining events. This behavior could likely change the way seasons should be planned (Pogrebin, 2002). From an academic point of view, this finding suggests that there may be a demographic difference in how sequence effects are perceived and is left for future research to consider.

\section{Hypothesis $2 b$}

Hypothesis $2 b$ states that the preference for the placement of peak events should be different if customers are evaluating past bundles or future bundles. This hypothesis is supported by the work of Soman (2003), who found a different preference for that placement of low points in a service based on when the evaluation took place (before or after the experience). The literature is mixed on what to expect concerning where the preference of the peak is more likely; to end on a high note suggests that a late peak might be preferred from a past bundle and, similarly, a late peak might increase the anticipation of future events. Conversely, an early peak might entice customer to buy if they know they will be able to redeem high value more quickly from the bundle purchase.

Our results showed a preference for early peaks for past bundles, as the variable Days from Last Event to Peak Event was positive and significant (coeff. $=0.001 ; p<0.001$ ). This means that as the number of days from the peak event to the last event increased, repurchase probability was more likely. Similarly, we found a preference for early peaks for future bundles, as the variable Days from First Event 
to Peak Event was negative and significant (coeff. $=-0.001 ; \mathrm{p}<0.001$ ), which indicated that, as the number got smaller or closer to zero, repurchase probability increased. Since both past and future perceptions had the same preference (early peak), there was no support for our hypothesis.

The most likely explanation of our findings is in the prospective evaluation measure of both past and future bundles. As explained earlier, the ideal would be to have experienced evaluation of past events and prospective evaluation of future events, which our data does not include. By using prospective evaluation based on the demand of events before they happened, it may be unsurprising that we have the same results for both perspectives. However, our findings suggest a couple of important contributions: First, with a prospective evaluation of a discrete sequence, customers preferred an early peak over a late peak; second, prospective evaluations were likely the same regardless of past or future bundle perspective. The first contribution has managerial significance, which we will discuss in the next section. The second contribution suggested that it mattered less whether we used past or future perspective if we only had one type of evaluation to consider. The results from other parts of the model similarly suggest there is little difference between past and future perspective, for example, within the same model, past and future model fit was not significantly better for one perspective.

Hypotheses $2 c$ and $2 d$

We suspected that the end effect should have an impact on past bundles but not on future bundles. Instead, we found that the coefficients for the last event utility were consistently significant for both past and future perspectives. Given our prospective evaluations, this finding suggested that customers preferred a sequence in which there was something to anticipate at the end of the series; although the finding for a preference for early peaks suggested that the end might not have necessarily been the peak, just that it should have been high. We will discuss the implications of the past two findings more in detail in the next section.

Hypothesis $2 e$

Our final hypothesis was that the trend effect as measured by the slope would not significantly influence the repurchase decision of sequences that were discretely separated, as suggested by past literature. The coefficients for slope parameters are significant only in our final model, which included both past and future sequence effects (slope of past events: coef. $=1.664 ; p<0.05$ ); all remaining models provided insignificant estimated coefficients for slope variables. This finding suggested that as the event utility trend of a past bundle increased, customers were more likely to repurchase; however, 
trends of future bundles did not impact purchase decisions. Unlike the placement of the peak event, our results suggested that the trend effect was used for evaluation of past bundles, even with prospective evaluations, but predictably did not influence evaluations of future bundles, that is, customers could perceive an experienced trend but not an anticipated trend among discrete events. Knowing that the trend effect of discrete events is important only for evaluations of past sequences indicates that trend effects should be considered if retention and remembered utility are important, but less important if acquisition is of most importance.

\section{Managerial Implications}

In summary, our main findings are fourfold:

1. Longtime loyal customers are more likely to repurchase when higher peak events are included; new customers are less likely to repurchase when higher peak events are included.

2. Under prospective evaluations, an early peak event placement improves repurchase probabilities.

3. As the event utility of the last event increases, repurchase probability increases under both past and future season perspectives.

4. Trend effects impact past bundle evaluations, but not future bundle evaluations.

There are two broad implications of these findings that lead to optimal bundle design. First, the findings give direction about which events should be bundled together. The first finding suggests that a bundle highly leveraged by a high utility event is not likely to retain new customers at least not in situations in which individual events can be purchased. By segmenting customers and designing bundles to target individual segments, service designers can group events together differently depending on the target segment's taste for peak events. Bundles targeted to loyal customers could include an expected high utility event combined with lower utility events and expect positive impact on repurchase probabilities. However, our results suggest that the bundle targeted to newer customers should consist of events that are more similar in utility.

A second implication of the findings gives direction about when events should be scheduled within a service bundle. The second finding suggests that peak events should be placed early in order to maximize perceived perception. We must interpret these results in the context of prospective evaluation, mainly that customer prefer to anticipate an earlier peak. This result would lead service designers to schedule a more anticipated popular event earlier in the season. 
Percent increase in average predicted probability of repurchase co-varied across min and max of significant sequence variables.

\begin{tabular}{|c|c|c|c|c|}
\hline \multirow[b]{2}{*}{ Customer type } & \multicolumn{4}{|c|}{ Co-varied varaible } \\
\hline & $\begin{array}{l}\text { Future last } \\
\text { event utility }\end{array}$ & $\begin{array}{l}\text { Days from future } \\
\text { first event to future } \\
\text { peak event }\end{array}$ & $\begin{array}{l}\text { Slope of past event } \\
\text { utility over time }\end{array}$ & $\begin{array}{l}\text { Days from past } \\
\text { peak event to past } \\
\text { last event }\end{array}$ \\
\hline Longtime loyal & $18 \%$ & $2 \%$ & $4 \%$ & $2 \%$ \\
\hline Fickle & $50 \%$ & $5 \%$ & $11 \%$ & $5 \%$ \\
\hline Upcoming Loyal & $78 \%$ & $7 \%$ & $16 \%$ & $7 \%$ \\
\hline \multirow[t]{2}{*}{ New } & $104 \%$ & $9 \%$ & $20 \%$ & $9 \%$ \\
\hline & $\begin{array}{l}\operatorname{Min}=1.18 \\
\operatorname{Max}=39.36\end{array}$ & $\begin{array}{l}\operatorname{Min}=0 \\
\operatorname{Max}=250\end{array}$ & $\begin{array}{l}\operatorname{Min}=-0.091 \\
\operatorname{Max}=0.099\end{array}$ & $\begin{array}{l}\operatorname{Min}=0 \\
\operatorname{Max}=251\end{array}$ \\
\hline \multicolumn{5}{|c|}{ Percentage increase $=\frac{\text { (average probability with highest value-average probability with lowest value) }}{\text { average probability with wowwest value }}$} \\
\hline
\end{tabular}

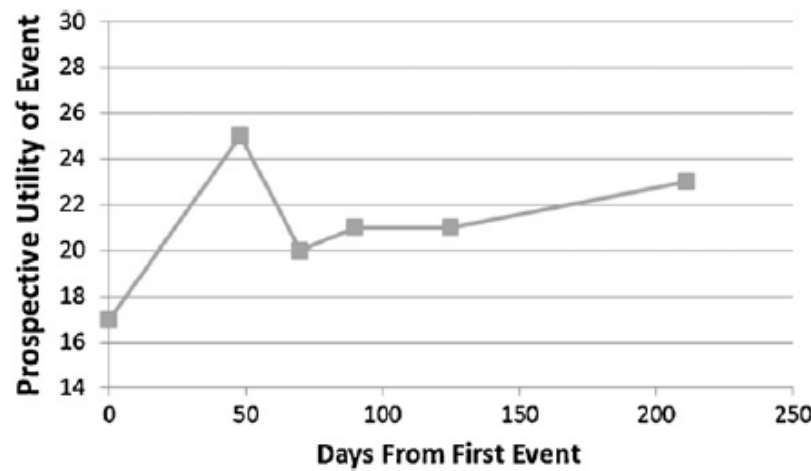

Fig. 1. Speculated "optimal" bundle and schedule with early peak, positive trend, and high last event utility.

Our final finding suggests that the trend of a discrete sequence is less important to prospective evaluations of future bundles, but is used in considering past bundles. The implication of this finding is that the trend of the event utilities is not likely to impact initial purchase of a bundle; however, after experiencing the bundle, customers are more likely to repurchase if the predetermined trend was low to high.

This positive trend preference, combined with a preference for early peaks and a preference for high last-event utility (our third finding) seem to contradict one another; mainly, if a peak is placed early, a positive trend might be difficult, and the last event is not the peak and thus not maximized. In order to better understand the magnitude of repurchase probabilities under different scenarios, we calculated the repurchase probabilities with the estimates of Model 3 (future and past sequence variables), covarying values of the significant sequence variables. Leaving all other variables untouched, we estimated the repurchase probabilities for each individual if the sequence variable varied across the range of historical values, that is, at its lowest value and highest value. Table 8 shows the average percent increase of repurchase probabilities from the worst possible value to the best value of each sequence variable across the four customer types. 
These results provide a level of the effect size of our results and suggest that the future lastevent utility is the most influential among the sequence variables across the range of historical values. New customers had an average of $28.2 \%$ probability of repurchase under the lowest last-event utility (1.18), and an average of $57.5 \%$ probability of repurchase under the highest last-event utility (39.36)-a $104 \%$ increase. This result implies that the last event utility is perhaps the most important of all events, even controlling for total bundle utility.

While it is outside the scope of this research, we can consider the profile of an optimal event schedule using our findings. It would seem that an optimal bundle would have two higher utility events-the highest of which is placed early in the schedule (perhaps the second or third placement) and the lower placed at the end. The remaining events are ordered and scheduled from lowest to highest. Fig. 1 shows what this might look like in an experience profile.

\section{Conclusions}

At the highest level, our research has provided a degree of empirical support for sequence effect theories set forth by previous researchers. Uniquely, we found evidence that these effects can be found in sequences of discrete experiences that elapse over an entire subscription season, while past research has been focused on single interactions. The model shows that scheduling sequence decisions may impact repurchase behavior of customers and that prospective demand-based evaluations of event utilities can be used in these sequencing decisions. More specifically, using prospective evaluations of event utilities, we found evidence that customers were influenced by the placement of a peak event, the utility of the last event, and the trend of a previous bundle. We also found difference between customer loyalty segments in their perception of bundles that were highly leveraged by high peak events. Finally, we provided an example of how to elicit and test for sequence effects using only archival data.

\section{Limitations and Future Research Directions}

We acknowledge that our model suffers from self-selection bias, since customers choose which subscription to purchase and only customers that buy are modeled for repurchase. Although this bias may make it difficult to discern causality (vs. correlation) for many of our independent variables, we are concerned primarily about the sequence variables. It may be the case that customers who repurchase more use the future sequence of a subscription as an attribute of initial choice modeling, but that in itself is also an interesting finding. Since we have controlled for as many other product and customer attributes, we feel that the effects of the sequence variables are distinct. Whether they cause a 
repurchase or if customers who tend to repurchase prefer a specific sequence, the results still support the managerial implications of sequencing events in a specific way. Future research should test the causality of sequence effects by using additional controlled experimentation.

Creating subscription bundles and scheduling an entire season of events is not as trivial as moving an event to a different place and time. Some events have constraints placed on them by the performers (e.g., a guest artist is in town) and others may be seasonal by nature (e.g., a Christmas show). We could easily find an optimal sequence given a fixed set of events, but the more challenging problem is to find an optimal schedule across all bundles and events. The problem becomes much more challenging and interesting if events are not only scheduled, but also put into the appropriate bundle. This problem and its insights are left for future research, most likely solved with heuristic optimization methods.

Although our research is embedded in a specific service bundle context, we believe that the effect of utility-based scheduling can be realized outside the context of the performing arts. Certainly, the scheduling of sporting events, conferences, courses, and tour packages has similar bundling attributes that make it akin to scheduling based on estimated utilities. For example, individual National Basketball Association (NBA) teams likely do not have much to say about when games are scheduled; however, each team does bundle and sell a subset of their own games. Each game has a demand or expected prospective utility that can be determined based on historical rivalries, team and conference standings, and the expected importance of games. NBA team management can create bundles that will result in specific expected utility sequences. Certainly the experienced utility of a game is based largely on the outcome (win or loss), but since our research dealt with and found evidence for sequence effects in prospective evaluations, we could expect basketball fans to behave similarly as our performing arts patrons concerning expected event evaluations, that is, preference for early peaks, high ends, and positive trends. The specific recommendations that we have made above may not be applicable to all service bundles, but designers of all services should consider the sequence an attribute worth considering.

As we have discussed several times throughout this article, future research on this topic should strive to include and understand the difference between retrospective evaluations and prospective evaluations in discrete theme bundles. It seems a harder case to find support for sequence effects in prospective evaluations, as we have. It will probably not be surprising to find sequence effects among retrospective evaluations, given that we can find them in prospective evaluations; however, we can only speculate on what the differences might be between the two types of evaluations and what it might 
mean to service design. We have demonstrated a way to derive prospective evaluations from archival data; however, experienced utility is likely more challenging to collect through surveys, second party post-event reviews, and ratings of events, or some other inner-experience measurement (e.g., applause meter, social media activity during segment). Combining archival data with collected experiential utility data are an appropriate next step in this research stream and will likely add to the understanding of how to implement sequence effects into service design.

If future research shows that peak placement for experienced utility is different than prospective utility, service designers might be challenged to create a sequence that has an early prospective peak, and a late experience peak. This might be accomplished by heavily publicizing an earlier event, while secretly planning for a more exciting later event. The danger in this approach would be a reduction in the prospective value of the bundle and the future event, which may result in lower overall ticket sales, that is, nonsubscription sales for a later peak might suffer because of the loss of publicity. Similarly, the final event experienced utility could be made high in some way other than scheduling a high-demand event. For example, service designers could plan to make one event more memorable through some unexpected within-event activity (e.g., giving away a door prize, unexpected opening act, experience-centric activity). Our results showed that new customers were not impacted by the presence of a prospective peak event; however, perhaps they will be receptive to the planned, but unexpected, experienced utility peaks. There is more research needed in order to validate that experienced peaks can be created separate from prospective peaks and that their placement is preferred differently.

Business scholars can certainly learn much from those that design experiences. As noted, service operations management and, more specifically, experience management can be compared to choreography attempting to elicit particular emotional and behavioral responses. In this article, we addressed a key part of choreography of a service: the importance of timing of high and low points across discrete service segments. There is much more to learn about how to elicit different levels of utility of service segments, and we look forward to a continued research stream surrounding these topics.

\section{References}

Ariely, D., 1998. Combining experiences over time: the effects of duration, intensity changes and on-line measurements on retrospective pain evaluations. Journal of Behavioral Decision Making 11 (1), 19-45. 
Ariely, D., Carmon, Z., 2000. Gestalt characteristics of experiences: the defining features of summarized events. Journal of Behavioral Decision Making 13 (2), 191-201, http://dx.doi.org/10.1002/(SICI)1099-0771(200004/06)13:2<191:: AID-BDM330>3.0.CO;2-A.

Ariely, D., Zauberman, G., 2000. On the making of an experience: the effects of breaking and combining experiences on their overall evaluation. Journal of Behavioral Decision Making 13, 219-232.

Ariely, D., Zauberman, G., 2003. Differential partitioning of extended experiences. Organizational Behavior and Human Decision Processes 91 (2), 128-139.

Aydin, G., Ziya, S., 2008. Pricing promotional products under upselling. Manufacturing and Service Operations Management 10 (3), 360.

Baumgartner, H., Sujan, M., Padgett, D., 1997. Patterns of affective reactions to advertisements: the integration of moment-to-moment responses into overall judgments. Journal of Marketing Research, 219-232.

Ben-Akiva, M., Lerman, S., 1985. Discrete Choice Analysis: Theory and Application to Travel Demand, 1st ed. The MIT Press, Cambridge, MA.

Bitran, G.R., Caldentey, R., 2003. An overview of pricing models for revenue management. Manufacturing and Service Operations Management 5 (3), 203-229.

Bitran, G.R., Ferrer, J.-C., 2007. On pricing and composition of bundles. Production and Operations Management 16 (1), 93-108.

Bitran, G.R., Ferrer, J.-C., Rocha e Oliveira, P., 2008. OM forum - managing customer experiences: perspectives on the temporal aspects of service encounters. Manufacturing and Service Operations Management 10 (1), 61-83.

Bolton, R.N., Lemon, K.N., Bramlett, M.D., 2006. The effect of service experiences over time on a supplier's retention of business customers. Management Science 52 (12), 1811-1823.

Carmon, Z., Kahneman, D., 1996. The experienced utility of queuing: real time affect and retrospective evaluations of simulated queues. Working paper, Duke University.

Chase, R.B., 2004. It's time to get to first principles in service design. Managing Service Quality 14 (2/3), 126-128.

Chase, R.B., Dasu, S., 2001. Want to perfect your company's service? Use behavioral science. Harvard Business Review 79 (6), 78-84, 147. PMID: 11408979.

Chase, R.B., Dasu, S., 2008. Psychology of the Experience: The Missing Link in Service Science. Service Science, Management and Engineering Education for the 21st Century, Service Science: Research and Innovations in the Service Economy. Springer, New York, NY, pp. 35-40. 
Cohen, J., 1968. Multiple regression as a general data-analytic system. Psychological Bulletin 70 (6 Pt. 1), 426-443, http://dx.doi.org/10.1037/h0026714.

Cook, L.S., Bowen, D.E., Chase, R.B., Dasu, S., Stewart, D.M., Tansik, D.A., 2002. Human issues in service design. Journal of Operations Management 20 (2), 159- 174.

Davidson, M., 2003. An integrated approach to service quality in hotels. Journal of Quality Assurance in Hospitality and Tourism 4 (1), 71-85.

Davidson, M., Manning, M.L., Brosnan, P., Timo, N., 2001. Organizational climate, perceived customer satisfaction, and revenue per available room in four- and five-star Australian Hotels. Tourism Analysis 6 (2), 123-137.

Fredrickson, B.L., Kahneman, D., 1993. Duration neglect in retrospective evaluations of affective episodes. Journal of Personality and Social Psychology 65 (1), 45-55, PMID: 8355141.

Gaeth, G.J., Levin, I.P., Chakraborty, G., Levin, A.M., 1991. Consumer evaluation of multi-product bundles: an information integration analysis. Marketing Letters 2 (1), 47-57.

Gensch, D.H., Recker, W.W., 1979. The multinomial, multiattribute logit choice model. Journal of Marketing Research 16 (1), 124-132.

Goldstein, S.M., Johnston, R., Duffy, J.A., Rao, J., 2002. The service concept: the missing link in service design research? Journal of Operations Management 20 (2), 121-134.

Goodale, J.C., Verma, R., Pullman, M.E., 2003. A market utility-based model for capacity scheduling in mass services. Production and Operations Management 122, 165-185, http://dx.doi.org/10.1111/j.1937-5956.2003.tb00499.x.

Green, P.E., Krieger, A.M., 1989. Recent contributions to optimal product positioning and buyer segmentation. European Journal of Operational Research 41 (2), 127-141.

Green, P.E., Krieger, A.M., 1991. Product design strategies for target-market positioning. Journal of Product Innovation Management 8 (3), 189-202.

Grove, S.J., Fisk, R.P., 2001. Service theater: an analytical framework for services marketing. Services Marketing, 83-92.

Guiltinan, J.P., 1987. The price bundling of services: a normative framework. Journal of Marketing 51 (2), 74-85.

Haisley, E., Loewenstein, G., Simon, H., 2011. It's not what you get but when you get it: the effect of gift sequence on deposit balances and customer sentiment in a commercial bank. Journal of Marketing Research 48 (1), 103-115, http://dx.doi.org/10.1509/jmkr.48.1.103. 
Hansen, D.E., Danaher, P.J., 1999. Inconsistent performance during the service encounter: what's a good start worth? Journal of Service Research 1 (3), 227-235, http://dx.doi.org/10.1177/109467059913004.

Harlam, B.A., Krishna, A., Lehmann, D.R., Mela, C., 1995. Impact of bundle type, price framing and familiarity on purchase intention for the bundle. Journal of Business Research 33 (1), 57-66.

Heskett, J.L., Sasser, W.E., Hart, C.W., 1990. Service Breakthroughs: Changing the Rules of the Game. Free Press, New York.

Ho, T.H., Zheng, Y.-S., 2004. Setting customer expectation in service delivery: an integrated marketingoperations perspective. Management Science 50 (4), 479-488.

Hsee, C.K., Abelson, R.P., Salovey, P., 1991. The relative weighting of position and velocity in satisfaction. Psychological Science 2 (4), 263-266.

Johnston, R., 1995. The zone of tolerance: exploring the relationship between service transactions and satisfaction with the overall service. International Journal of Service Industry Management 6 (2), 46-61.

Kahneman, D., Fredrickson, B.L., Schreiber, C.A., Redelmeier, D.A., 1993. When more pain is preferred to less: adding a better end. Psychological Science 4 (6), 401-405, http://dx.doi.org/10.1111/j.1467-9280.1993.tb00589.x.

Kahneman, D., Wakker, P.P., Sarin, R., 1997. Back to bentham? Explorations of experienced utility. Quarterly Journal of Economics 112 (2), 375-405, http://dx.doi.org/10.1162/003355397555235.

Kim, H.B., Kim, W.G., 2005. The relationship between brand equity and firms' performance in luxury hotels and chain restaurants. Tourism management 26 (4), 549-560.

Kim, H.B., Kim, W.G., An, J.A., 2003. The effect of consumer-based brand equity on firms' financial performance. Journal of Consumer Marketing 20 (4), 335-351.

Kimes, S.E., 1999. The relationship between product quality and revenue per available room at holiday inn. Journal of Service Research 2 (2), 138-144, http://dx.doi.org/10.1177/109467059922002.

Kimes, S.E., 2001. How product quality drives profitability. The Cornell Hotel and Restaurant and Administration Quarterly 42 (3), 25-28.

LaBarbera, P.A., Mazursky, D., 1983. A longitudinal assessment of consumer satisfaction/ dissatisfaction: the dynamic aspect of the cognitive process. Journal of Marketing Research 20 (4), 393-404.

Langer, T., Sarin, R., Weber, M., 2005. The retrospective evaluation of payment sequences: duration neglect and peak-and-end effects. Journal of Economic Behavior and Organization 58 (1), 157175, http://dx.doi.org/10.1016/ j.jebo.2004.01.001. 
Loewenstein, G., 1987. Anticipation and the valuation of delayed consumption. The Economic Journal 97 (387), 666-684.

Loewenstein, G., Prelec, D., 1993. Preferences for sequences of outcomes. Psychological Review 100 (1), 91-108.

Loewenstein, G., Sicherman, N., 1991. Do workers prefer increasing wage profiles? Journal of Labor Economics 9 (1), 67-84.

Luce, R.D., 1959. Individual Choice Behavior. Wiley, New York, NY.

McFadden, D., 1980. Econometric models for probabilistic choice among products. The Journal of Business 53 (3), S13-S29.

Millar, P., 2006. Using the Bayesian Information Criterion (BIC) to judge models and statistical significance. In: North American Stata Users' Group Meetings 2006, Stata Users Group, Retrieved from: http://econpapers.repec.org/paper/ bocasug06/1.htm

Miron-Shatz, T., 2009. Evaluating multiepisode events: boundary conditions for the peak-end rule. Emotion 9 (2), 206.

Moore, W.L., Louviere, J.J., Verma, R., 1999. Using conjoint analysis to help design product platforms. Journal of Product Innovation Management 16 (1), 27-39.

Morgan, L.O., Daniels, R.L., Kouvelis, P., 2001. Marketing/manufacturing trade-offs in product line management. IIE Transactions 33 (11), 949-962.

Oliver, R.L., 1980. A cognitive model of the antecedents and consequences of satisfaction decisions. Journal of Marketing Research 17 (4), 460-469, http://dx.doi.org/10.2307/3150499.

Parasuraman, A., Zeithaml, V.A., Berry, L.L., 1985. A conceptual model of service quality and its implications for future research. The Journal of Marketing 49 (4), 41-50, http://dx.doi.org/10.2307/1251430.

Pine, B.J., Gilmore, J.H., 1998. Welcome to the experience economy. Harvard Business Review 76 (4), 97-105.

Pogrebin, R., 2002, October 16. Uncertain Times: Impulse Buyers Replace Ticket Subscribers. New York Times.

Pullman, M.E., Goodale, J.C., Verma, R., 2000. Service capacity design with an integrated market utilitybased method. New Service Development: Creating Memorable Experiences, 111-137.

Pullman, M.E., Gross, M.A., 2004. Ability of experience design elements to elicit emotions and loyalty behaviors. Decision Sciences 35 (3), 551-578, http://dx.doi.org/10.1111/j.00117315.2004.02611.x. 
Pullman, M.E., Moore, W.L., 1999. Optimal service design: integrating marketing and operations perspectives. International Journal of Service Industry Management 10 (2), 239-261.

Raman, N., Chhajed, D., 1995. Simultaneous determination of product attributes and prices, and production processes in product-line design. Journal of Operations Management 12 (3/4), 187204.

Redelmeier, D.A., Kahneman, D., 1996. Patients' memories of painful medical treatments: real-time and retrospective evaluations of two minimally invasive procedures. Pain 66 (1), 3-8, PMID: 8857625.

Rosenthal, E.C., Zydiak, J.L., Chaudhry, S.S., 1995. Vendor selection with bundling. Decision Sciences 26 (1), 35-48, http://dx.doi.org/10.1111/j.1540- 5915.1995.tb00836.x.

Rust, R.T., Zahorik, A., 1993. Customer satisfaction, customer retention, and market share. Journal of Retailing 69 (2), 193-215.

Schoenherr, T., Mabert, V.A., 2008. The use of bundling in B2B online reverse auctions. Journal of Operations Management 26 (1), 81-95, http://dx.doi.org/ 10.1016/j.jom.2007.05.001.

Shocker, A.D., Srinivasan, V., 1979. Multiattribute approaches for product concept evaluation and generation: a critical review. Journal of Marketing Research, 159-180.

Soman, D., 2003. Prospective and retrospective evaluations of experiences: how you evaluate an experience depends on when you evaluate it. Journal of Behavioral Decision Making 16 (1), 3552.

Soman, D., Shi, M., 2003. Virtual progress: the effect of path characteristics on perceptions of progress and choice. Management Science, 1229-1250.

Stremersch, S., Tellis, G.J., 2002. Strategic bundling of products and prices: a new synthesis for marketing. The Journal of Marketing, 55-72.

Thaler, R.H., Johnson, E.J., 1990. Gambling with the house money and trying to break even: the effects of prior outcomes on risky choice. Management Science 36 (6), 643-660.

Verhoef, P.C., Antonides, G., de Hoog, A.N., 2004. Service encounters as a sequence of events: the importance of peak experiences. Journal of Service Research 7 (1), 53-64, http://dx.doi.org/10.1177/1094670504266137.

Verma, R., Thompson, G.M., Louviere, J.J., 1999. Configuring service operations in accordance with customer needs and preferences. Journal of Service Research 1 (3), 262-274, http://dx.doi.org/10.1177/109467059913007. 
Verma, R., Thompson, G.M., Moore, W.L., Louviere, J.J., 2001. Effective design of products/ services: an approach based on integration of marketing and operations management decisions. Decision Sciences 32 (1), 165-194, http://dx.doi.org/ 10.1111/j.1540-5915.2001.tb00957.x.

Voss, C.A., 2004. Trends in the Experience and Service Economy: The Experience Profit Cycle. London Business School, London, UK.

Voss, C.A., Roth, A.V., Chase, R.B., 2008. Experience, service operations strategy, and services as destinations: foundations and exploratory investigation. Production and Operations Management 17 (3), 247-266, http://dx.doi.org/10.3401/ poms.1080.0030.

Zomerdijk, L.G., Voss, C.A., 2010. Service design for experience-centric services. Journal of Service Research 13 (1), 67-82, http://dx.doi.org/10.1177/ 1094670509351960. 